\title{
Design de produção e a construção do sentido em Meu malvado favorito
}

\section{Production design and the sense-generating in Despicable me}

\author{
Rafael Coelho de Moraes \\ Especialista em Design de Interação pela Universidade do Vale do Itajaí (Univali) - raafaa.c.m@gmail.com - \\ http://orcid.org/0000-0003-0189-3368 \\ Murilo Scoz \\ Doutor em Design pela Pontifícia Universidade Católica do Rio de Janeiro (PUC-Rio). Professor da Universidade do \\ Estado de Santa Catarina (Udesc) - muriloscoz@gmail.com - http://orcid.org/0000-0001-7003-8133
}

\begin{abstract}
Resumo
Identificada em outros momentos como atividade de direção de arte ou cenografia, a concepção visual de elementos cinematográficos relativos aos cenários, objetos cênicos, artefatos, locações e produtos gráficos de um filme estão atualmente sob os cuidados do chamado design de produção (ou production design). Ao utilizar métodos e ferramentas de projeto, o design de produção configura-se como um processo de estruturação plástico e visual dos múltiplos elementos compositivos dos textos fílmicos. Buscando apresentar a importância narrativa da atividade, propõe-se no presente artigo realizar uma análise de um objeto audiovisual da série filmográfica "Meu malvado favorito", tendo como base o modelo de percurso gerativo do sentido proposto pela semiótica greimasiana. A análise tem como objetivo demonstrar a articulação dos elementos visuais do filme na estruturação de sua narrativa, o que se dá por meio da materialização de conceitos abstratos em artefatos e objetos cênicos específicos, de forma que a plasticidade da animação teve importante papel na materialização do significado de antagonismo que a produção desejava representar.
\end{abstract}

Palavras-chave: Cinema - Semiótica. Semiótica discursiva. Percurso gerativo de sentido. Design de produção.

\begin{abstract}
Identified at other times as an art direction or stage set, the visual conception of cinematographic elements relating to the scenarios, stage objects, artifacts, locations and graphic products of a film is currently under the care of so-called production design. By using design methods and tools, the production design is configured as a process of plastic and visual structuring of the multiple compositional elements of the filmic texts. Seeking to present the narrative importance of the activity, we propose in the present article an analysis of an audiovisual object of the film series "My favorite evil", based on the sense-generating route proposed by greimasian semiotics. The analysis aims to demonstrate the articulation of the visual elements of the film in the structuring of its narrative, which occurs through the materialization of abstract concepts in artifacts and specific scenic objects, so that the plasticity of the animation had an important role in the materialization of the meaning of antagonism that the production wanted to represent.
\end{abstract}

Keywords: Movie theater - Semiotics. Discursive semiotics. Sense-generating route. Production design.

Recebido em: 04/12/2017

Aceito em: 21/05/2019 


\section{INTRODUÇÃO}

Entre muitas formas de atuação do profissional de design, destacam-se as possibilidades abertas pelo campo do design de produção. Ligado à criação e formatação de elementos diegéticos em produtos audiovisuais, o designer de produção atua no alinhamento de objetos que entram na composição complexa de filmes, séries, animações etc. Fazem parte do grupo de artefatos as famílias tipográficas, a paleta cromática, as formas gráficas, os utensílios, os trajes e diversos outros elementos expressivos que constroem as narrativas audiovisuais.

Conforme apontado por Hollis (2001), por volta dos anos 1930, com a profissionalização da produção cinematográfica, os diretores de arte dos grandes estúdios passaram a adotar processos análogos aos do design gráfico, o que também foi observado no domínio da publicidade e na criação editorial das revistas e jornais. Com o desenvolvimento exponencial da indústria do cinema, tornou-se bastante comum encontrar designers envolvidos na criação de materiais de divulgação das obras, tanto na produção de cartazes como no processo de concepção dos créditos de abertura dos filmes. Na década de 1960, um dos profissionais de maior notoriedade foi Saul Bass, que colaborou com grandes nomes do cinema, tendo alcançado fama internacional por meio de projetos em parceria com Alfred Hicthcock. No cinema brasileiro, tem grande destaque o trabalho de Lygia Pape, em especial nas obras de Nelson Pereira dos Santos durante o período do Cinema Novo. Contudo, com a consolidação da atividade do design, muitos processos metodológicos de projeto passaram também a ser incorporados na esfera da produção das obras. E buscando dar forma às visões de diferentes cineastas, designers passaram a atuar na criação dos universos ficcionais imaginados, para construir ambientes, utensílios, vestimentas e outros objetos que caracterizem o teor da narrativa. Assim, o design de produção (ou production design, em inglês) passou a operar no alinhamento dos diversos elementos narrativos das obras, promovendo a coesão dos diferentes grupos de elementos empregados pela linguagem do cinema.

Nesse artigo, busca-se explorar as possibilidades do design de produção a partir da observação de objetos cênicos envolvidos no arranjo narrativo de uma obra de ficção animada. Para tanto, toma-se como objeto o filme "Meu malvado favorito", construindo formalmente a análise a partir dos perfis identitários de seus personagens. Para demonstrar tais operações, partese do quadro teórico da semiótica narrativa proposta por Greimas (1975), com o intuito de caracterizar a maneira como a conceptualização dos personagens está construída, e como a relação 
de antagonismo entre eles é tomada como base para a definição da plasticidade e das formas presentes na produção.

\section{UM FILME COMO CÓRPUS DE ANÁLISE}

"Meu malvado favorito" é um filme de animação 3D norte-americano lançado em 2010 pela Universal Studios e a Illumination Entertainment. Dirigida por Pierre Coffin e Chris Renaud, a produção arrecadou mais de 540 milhões de dólares em bilheterias, tornando-se, na época do lançamento, a quarta animação com maior bilheteria da história.

O primeiro filme da franquia apresenta a história de Gru, um personagem cômico em sua trajetória para se transformar no maior vilão do mundo. Neste percurso, marcado pela competição com outro vilão que persegue o mesmo objetivo, Gru vai se transformando e assumindo o papel de herói, o que cria situações inusitadas.

O filme inicia com o desaparecimento de uma das pirâmides do Egito. Ao longo da narrativa, o extravio é atribuído ao personagem Vector, rival do protagonista, o qual persegue o título de maior vilão da história. Isso funciona como uma ameaça a Gru, que passa a ser mostrado como um vilão já ultrapassado. Para provar suas habilidades e seu talento como vilão, Gru planeja e executa um feito ainda mais impactante: o roubo da lua. Para alcançar seu objetivo, cria um plano envolvendo três meninas órfãs, que o auxiliam desavisadamente, acreditando estarem sendo adotadas pelo personagem. Gru utiliza as meninas como uma espécie de distração para seu rival, enquanto invade sua fortaleza em busca de uma arma roubada por Vector, ou seja, trata-se da situação do ladrão que rouba outro ladrão. Isso desencadeia o confronto direto entre os dois arquivilões e expõe seus diferentes modos de agir.

O elemento surpresa da história está ligado à afeição que Gru desenvolve pelas órfãs na sequência das ações. Enquanto o plano é executado, Gru se vê no papel de pai, aconselhando, ajudando, protegendo e se envolvendo com as três meninas. Estas novas preocupações atrapalham o andamento do roubo da lua, o que incomoda o assistente do protagonista, Dr. Nefário. Alegando que com as meninas por perto Gru estaria perdendo o foco, o assistente as leva de volta para o orfanato depois delas cumprirem sua parte da missão. Resignado, Gru segue com o planejado e consegue seu objetivo: viaja ao espaço, utiliza a arma roubada de Vector para diminuir o tamanho da lua e toma posse da mesma. Contudo, no exato momento em que consegue de fato capturar o 
agora diminuto corpo celeste com suas mãos, Gru sente falta das meninas e decide retornar, lembrando-se de ter prometido assistir ao espetáculo de balé que elas apresentariam. Ao chegar no teatro, muito atrasado e após o término da apresentação, Gru descobre que Vector havia estado ali e sequestrado as órfãs e como resgate espera que Gru lhe entregue a lua. Gru atende ao rival, mas Vector não devolve as garotas, fazendo com que Gru se arrisque para salvá-las, provando assim a importância delas para ele e obtendo o perdão por tê-las devolvido à casa de adoção. O desfecho da história se dá com a reconciliação entre o protagonista, seu assistente, sua mãe e as meninas, que passam a formar uma espécie de família.

Apresentou-se um resumo do texto cinematográfico tomado como córpus e na sequência do trabalho busca-se demonstrar as possibilidades do modelo semiótico greimasiano para a análise da articulação entre os conteúdos do filme e as formas utilizadas para construir sua coerência gráfica, como produto da ação do design de produção.

\section{UM MODELO PARA ANÁLISE AUDIOVISUAL}

O modelo semiótico greimasiano baseia-se no processo de criação de um texto qualquer. Para a semiótica, tudo é texto, ou seja, toda obra produto de linguagem - seja literária, cinematográfica, teatral ou outra - é considerada um arranjo textual. Partindo de tal premissa, para fins de análise, cumpre reconhecer que o processo de criação sempre prevê um trajeto do plano das ideias ao plano da forma finalizada, ou seja, do "abstrato para o concreto". Assim, numa análise, pode-se imaginar que o processo da produção do sentido também segue tal esquema.

Partindo de tal aspecto, Greimas (1975) propõe um modelo geral para todos os textos, chamado Percurso Gerativo do Sentido. Para Fiorin (2015), o percurso é uma sucessão de patamares que mostra como se produz e se interpreta o sentido, em um processo que ocorre do mais simples ao mais complexo, do mais abstrato ao mais concreto. Para o autor, os patamares aqui apontados correspondem a três níveis: o profundo ou fundamental, o narrativo e o discursivo. Pelo exposto, pode-se concluir que enquanto o processo de criação implica a formalização de ideias abstratas (síntese), o seu contrário (análise) implica a reconstrução das categorias iniciais a partir do concreto. Com ampla aplicabilidade, o modelo possibilita reconhecer que a estrutura de um texto qualquer (seja ele uma poesia, uma peça de teatro, um conto, um filme ou uma obra de arte) dialoga com o sentido pretendido pelo autor. Dito de outra maneira, forma e conteúdo operam em 
solidariedade, alinhadas à intenção de comunicação do enunciador, interessado na apresentação de um dado ponto de vista.

Trazida ao ambiente da produção audiovisual, esta lógica permite observar que um roteiro cinematográfico toma forma pela articulação de diferentes operações e escolhas realizadas pelo "autor" de um filme. Do figurino às locações, todos os elementos narrativos devem ser pensados a partir do conteúdo que se pretende transmitir, seguindo um rigoroso processo de planejamento visual, sonoro, gráfico, etc. A seguir, ao explorar as categorias do modelo do percurso gerativo, demonstram-se como as escolhas operadas pelo design de produção dialogam com o conteúdo narrativo do filme, organizado sobre uma ideia geral de oposição entre o bem e o mal.

\subsection{Nível fundamental}

O nível fundamental é o mais profundo do percurso gerativo de sentido e corresponde às estruturas semânticas profundas do texto, nas quais podem-se encontrar os investimentos semânticos mais abstratos operados pelo seu autor a fim de produzir o ordenamento dos valores de base. Como um esquema relacionado aos valores mais profundos da história, o nível fundamental do percurso gerativo abriga as oposições semânticas que dão base ao texto, ou seja, um conjunto de termos pressupostos que se definem reciprocamente numa relação de contrariedade (/morte/ e /vida/, /liberdade/ e /dominação/, /bem/ e /mal/, etc.). A partir dessa oposição, é organizada a estrutura elementar do texto em um modelo lógico, o chamado quadrado semiótico, o qual explicita implicações de contradição (/morte/ e /não morte/, por exemplo), e as implicações (/não morte/ e /vida/). Derivada da retórica de Aristóteles, a ferramenta do quadrado mostra-se útil à observação das transformações profundas do texto, dadas em termos de asserção e negação dos conceitos organizados no esquema.

Por esta razão, a análise do nível fundamental se estabelece pela identificação de valores abstratos gerais não exclusivos de um único texto, mas organizados sintaticamente segundo percursos de construção diferente.

\subsection{Nível narrativo}

Se no nível fundamental temos as bases semânticas profundas do texto, no nível imediatamente superior essas categorias começam a se organizar em estruturas narrativas mais 
concretas. O nível narrativo é, portanto, o nível intermediário do percurso gerativo, onde se observam as transformações sofridas pelo sujeito ao longo do texto, mediante provas de conquista ou supressão do que é perseguido. Para a semiótica, esta gramática da junção permite definir os sujeitos a partir de suas relações com os objetos, que não são as "coisas do mundo", mas os valores investidos naquilo que os sujeitos apresentam como seus objetivos narrativos, ou seja, como os propósitos de seus percursos e esforços.

O nível narrativo é definido por Barros (2011, p. 16) como,

[...]um espetáculo que simula o fazer do homem que transforma o mundo. Para entender a organização narrativa de um texto, é preciso, portanto, descrever o espetáculo, determinar seus participantes e o papel que representam na historiazinha simulada.

Nessa perspectiva, a sintaxe do nível narrativo busca compreender as transformações do sujeito, segundo o encadeamento de quatro diferentes fases: manipulação (ou contrato), competência, performance e sanção (FIORIN, 2015). Em cada uma das etapas desse percurso, o sujeito acaba exposto a algum tipo de determinação externa, o que implica uma transformação transitória e parcial na direção da realização de seu propósito. Nesse caminho, pode-se prever dois tipos de objetos: o modal - intermediário e necessário ao cumprimento da performance - e o de valor - fim último da narrativa (BARROS, 2011).

\subsection{Nível discursivo}

O nível discursivo é o mais superficial do percurso gerativo do sentido e, de acordo com Fiorin (2015), reveste de concretude as formas abstratas do nível narrativo. A sintaxe discursiva analisa três procedimentos de discursivização: actorialização, temporalização e espacialização, relacionadas a estratégias de projeção da enunciação no enunciado. Em outras palavras, dizem respeito a forma como o enunciador do texto (a projeção da imagem de seu autor) se coloca em relação com o enunciatário (a imagem de seu público). Por meio dessas operações, as quais correspondem a construção das categorias de pessoa, tempo e espaço, respectivamente, o discurso produz maior ou menor grau de objetividade, instaurando distintos modos de interlocução e, portanto, de sentido.

Já na semântica do nível discursivo, o percurso distingue duas operações que garantem a superfície mais "externa" do texto: a tematização - criação das formas conceituais abstratas mais 
específicas do discurso - e a figurativização - elementos mais concretos e reconhecíveis do mundo natural (BARROS, 2011). Aqui, percebe-se que o conceito de figurativo se opõe a ideia de abstrato, por recuperar no espaço do discurso elementos reconhecíveis por parte do enunciatário.

\section{ANÁLISE SEMIÓTICA DE “MEU MALVADO FAVORITO”}

Disciplina que se ocupa do processo de produção do sentido, a semiótica toma como ponto de partida o conceito de texto, ou seja, uma totalidade decomponível em partes coerentemente arranjadas, cujas relações possibilitam a significação. Por essa perspectiva, a análise aqui apresentada se constitui da observação da articulação dos três níveis do percurso gerativo no objeto fílmico em questão, a fim de compreender o modo como o design de produção atua para a coesão dos elementos narrativos, atuando para "descrever e explicar o que o texto diz e como ele faz para dizer o que diz" (BARROS, 2011, p. 7). Inicialmente descrevendo as duas dimensões de cada um dos níveis supracitados, que compõem o chamado eixo figurativo-narrativo, passa-se para uma articulação com as categorias próprias da plasticidade da obra audiovisual.

\subsection{Nível fundamental}

No percurso narrativo de Meu malvado favorito, pode-se identificar a oposição entre o bem e o mal, polos semânticos entre os quais os personagens transitam. Iniciando pela asserção de seu papel como vilão, temos a afirmação do mal em Gru, em seguida negada, para culminar com a afirmação de sua bondade. Esse percurso é apresentado por ações isoladas ao começo do filme, tanto quando Gru executa pequenos atos maldosos, como quando fura o balão de uma criança. No decorrer do filme, já envolvido com as meninas, o personagem passa a mostrar sua possibilidade de redenção, especialmente quando defende as órfãs das maldades de Vector. No final do filme temos a afirmação da bondade de Gru, ao salvar as meninas do Vector e devolver a lua para seu lugar, sendo reconhecido como herói.

A partir dessas ideias, pode-se propor um quadrado semiótico referente ao filme (figura 01). Em cada um dos momentos da narrativa, Gru se comporta como um personagem mau e bom, já que ele parece e quer ser malvado, porém se mostra um homem bom que se importa com o amor das meninas. As meninas, por sua vez, são personagens boas e não más, já que elas buscam no filme o amor de um pai/mãe pela via da adoção. Vector é considerado mau e não bom pois só 
almeja o título de maior vilão de todos os tempos, não importando o que ele tiver que fazer para alcançar o objeto do seu desejo. Por fim, os minions são personagens não bons e não maus: eles existem apenas para servir seu criador, não importando se é para roubar um raio encolhedor ou se para salvar a vida das meninas.

Figura 1 - Quadrado semiótico.
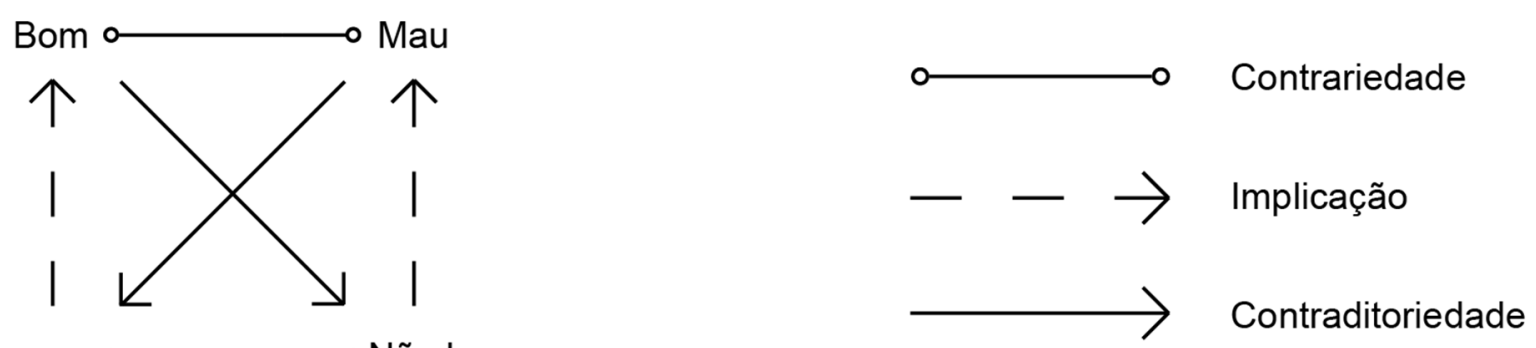

Não mau o ○Não bom

Fonte: elaborado pelos autores (2017).

Posicionando essas relações no quadrado semiótico construído anteriormente, obtemos o seguinte esquema (figura 02).

Figura 2 - Identidades das personagens em "Meu malvado favorito".
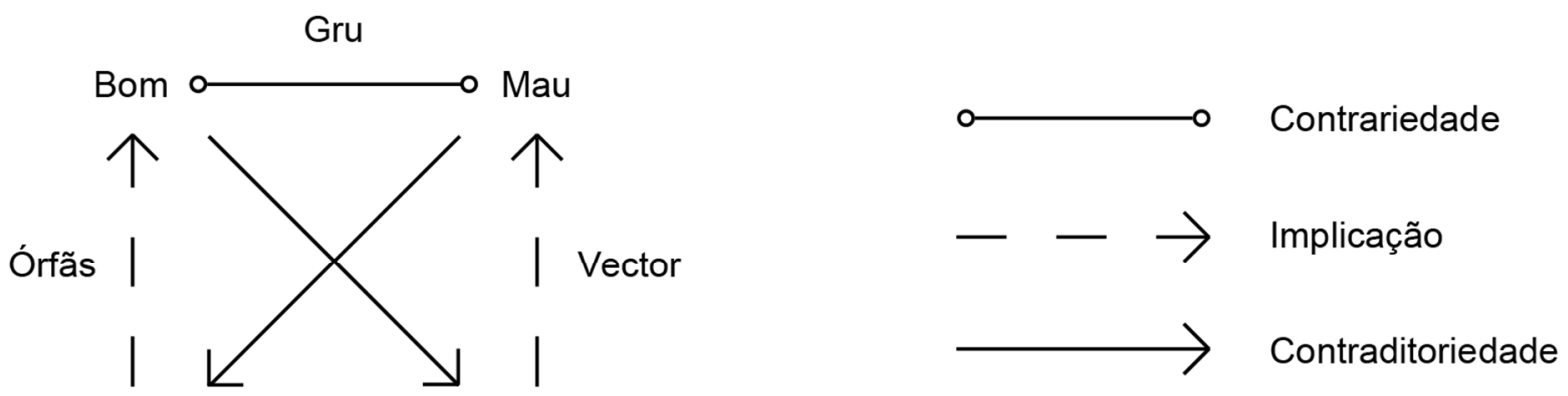

Não mau

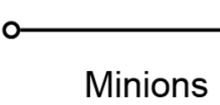

○ Não bom

Fonte: elaborado pelos autores (2017).

Na busca pela unidade do texto, utilizam-se reiterações de termos explorados na narrativa, o que semioticamente é tratado pelo conceito das chamadas isotopias, ou seja, a permanência de um sentido na cadeia do discurso. 
Em Meu malvado favorito, podem-se reconhecer algumas isotopias, como a relação de Gru com a sua mãe e a de Vector com o seu pai. Ambas as relações são construídas à base de cobrança, por parte dos pais e provação por parte dos filhos. Quanto à relação de rejeição entre Gru e sua mãe, outra isotopia é reconhecida, manifestando-se na situação das meninas órfãs rejeitadas pelos pais e moradoras de um orfanato.

Figura 3 - Relação de superioridade entre Srta. Hattie e as meninas órfãs.

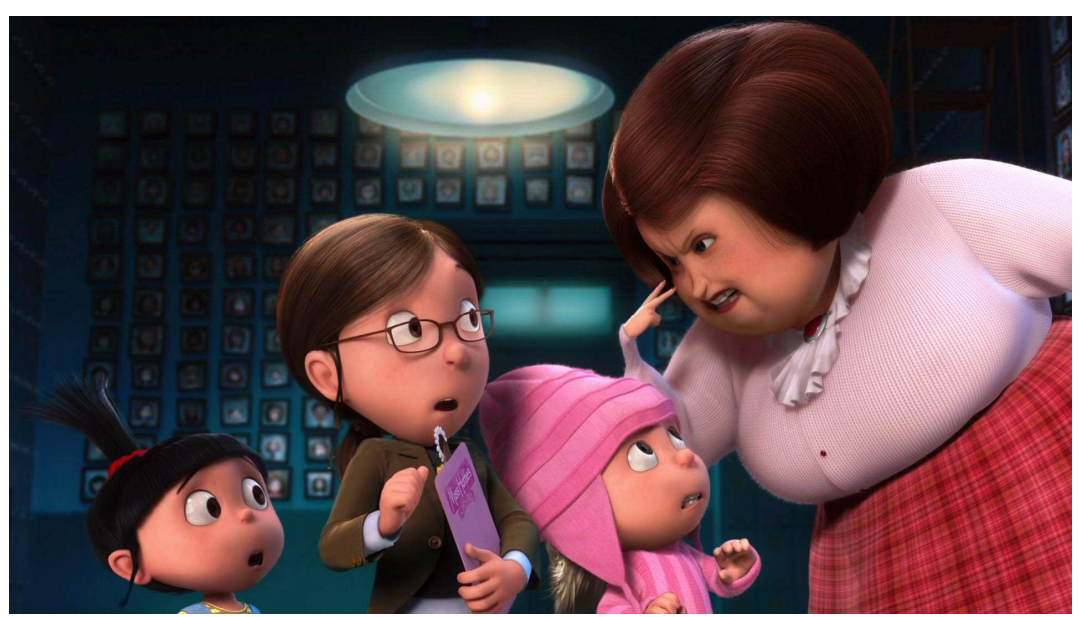

Fonte: frame extraído do filme Meu malvado favorito.

Existe ainda uma relação de superioridade repetida na narrativa. Entre a Srta. Hattie, dona do orfanato, e as meninas órfãs (figura 03), bem como entre o Sr. Perkins, dono do Banco do Mal, e Gru (figura 04). Em ambos os casos, os "superiores", Srta. Hattie e o Sr. Perkins, se posicionam de forma a humilhar e diminuir tanto Gru quanto as meninas. Visualmente são representados de forma parecida: tanto o Sr. Perkins quanto a Srta. Hattie são retratados sentados atrás de uma mesa, mais elevados do que o Gru e as meninas, reforçando a relação de superioridade/ inferioridade.

Outra isotopia encontrada está na "aceitação" das meninas, tanto por Gru quanto por Kyle, seu cachorro. No início da narrativa ambos fugiam delas, não permitiam aproximação. Porém, no final há a aceitação por parte dos dois. 
Figura 4 - Relação de superioridade entre Sr. Perkins e Gru.

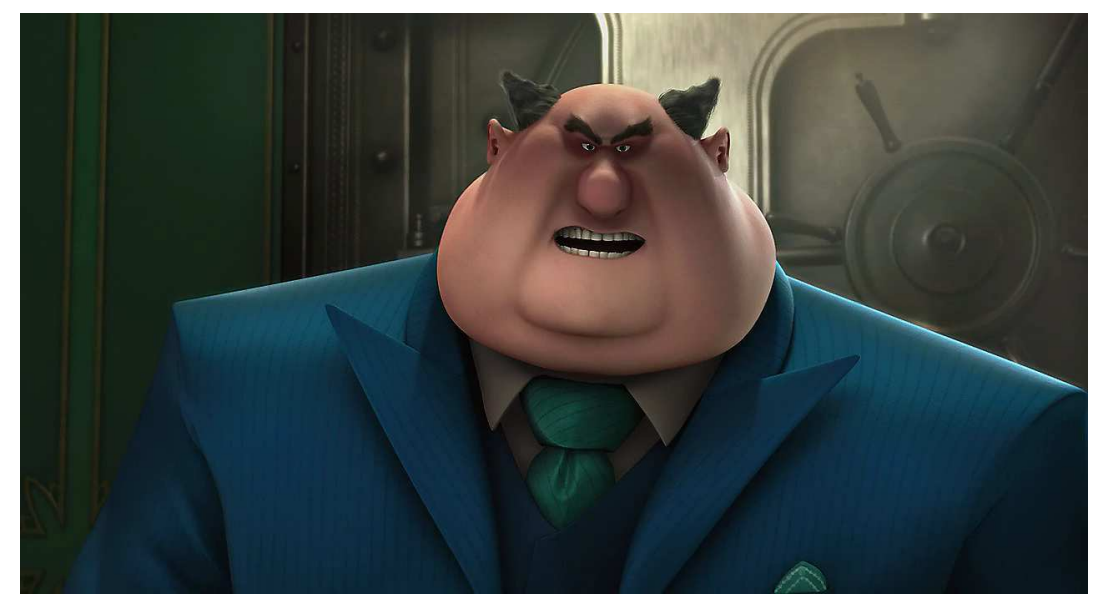

Fonte: frame extraído do filme Meu malvado favorito.

\subsection{Nível narrativo}

No filme em questão, podemos dizer que as órfãs são sujeitos disjuntos (separados) de uma figura paterna, apresentada como o objeto de valor perseguido. Enquanto para o personagem Vector, pode-se dizer que a superação dos feitos de Gru é o objeto de valor que o motiva. Assim, pode-se constatar que a relação com os objetos ajuda a descrever o estado dos sujeitos no decorrer da narrativa. Para Fiorin (2015), a narratividade é uma transformação entre dois estados diferentes, pressupondo que a narrativa mínima se dá quando há um estado inicial, uma transformação e um estado final. Segundo o autor, na sintaxe do nível narrativo pode-se considerar dois tipos de enunciados: aqueles de estado, cuja relação com os objetos é descrita, e aqueles de fazer, os quais estabelecem as transformações entre dois estados pela posse ou privação desses objetos. Os enunciados de estado são descritivos, apresentando sujeitos em conjunção (posse) ou disjunção (falta) com determinado objeto, enquanto os enunciados de fazer são constituídos por fases, que levam à transformação de estado do sujeito. Fiorin (2015) compreende que os textos envolvem uma sucessão de enunciados de ser e de fazer, articulados na sequência narrativa canônica ou percurso narrativo. Este se dá em quatro fases: (1) manipulação, (2) competência, (3) performance e (4) sanção.

Para a teoria narrativa semiótica, manipular significa levar alguém a fazer alguma coisa. $\mathrm{Na}$ fase da manipulação, um sujeito faz fazer, agindo sobre outro para levá-lo a querer e/ou dever fazer alguma coisa (FIORIN, 2015). Em outras palavras, o conceito da manipulação descreve as diferentes formas de interação entre sujeitos, por meio da circulação de objetos de valor. Assim, 
pode-se compreender que o sujeito manipulador age sobre o sujeito manipulado, levando-o a iniciar um percurso narrativo com vistas a atingir seu objetivo. Enquanto a fase da competência envolve o processo no qual o sujeito adquire as condições necessárias para agir, credenciando-se para a realização da chamada performance. Esta, por sua vez, é a fase da execução da ação que o sujeito foi manipulado a fazer. Por fim, o percurso deve se encerrar numa sanção (positiva ou negativa), dada ao sujeito por aquele actante que o manipulou, como resultado de um julgamento sobre sua performance.

No objeto analisado, há dois arcos narrativos, marcados por duas manipulações (Figura 05). No primeiro arco, mostra-se o roubo de uma das pirâmides do Egito, por um novo supervilão ainda desconhecido. O sujeito (Gru) é manipulado por provocação: há um novo vilão com feitos mais surpreendentes que Gru (m1). O sentido de provocação, ou seja, de projeção de uma imagem negativa de Gru, é reiterado pela fala do personagem Dr. Nefário: "tudo bem ser o segundo maior vilão". Para recuperar seu "título", Gru decide que seu grande feito será roubar a lua, que passa a ser seu novo objeto de valor. Para tal feito, correspondente à ideia semiótica de performance, Gru precisa roubar o raio encolhedor, ou seja, precisa adquirir um poder fazer que o competencializará para a ação. Após várias tentativas frustradas em roubar o raio, Gru descobre que o meio para realizar seu plano é por meio das meninas órfãs, que têm livre acesso à fortaleza de Vector. Esse tipo de elemento narrativo corresponde ao chamado objeto modal, ou seja, um objeto intermediário o qual o sujeito precisa conquistar antes de chegar à realização de sua performance. Tal é a natureza da relação de Gru com as meninas, que após a obtenção da arma de Vector, o protagonista é facilmente convencido a devolvê-las ao orfanato. Ao fim desse arco narrativo, Gru parte para o espaço e utilizando a arma roubada, consegue a posse da lua.

O segundo arco narrativo tem início exatamente nesse momento. Quando Gru conquista aquele que parecia seu objetivo maior (a lua e, por conseguinte, o título de maior vilão), ele percebe o quanto sentia falta das meninas que devolvera ao orfanato. Aqui, ocorre a segunda manipulação (m2), dada pela ausência da família e isso faz com que Gru busque as meninas no recital de balé. O objeto de valor agora passa a ser a redenção. Como já explanado, Gru descobre o sequestro engendrado por seu rival, o que coloca o protagonista em novo percurso narrativo. Para salvar as meninas e tê-las de volta como família (objeto de valor), ele deve abandonar a vilania e assumir um papel heroico. Gru age então com desprendimento, corre na direção de mísseis, soca 
um tubarão e se pendura na nave do Vector, tendo sucesso graças à coragem heróica demonstrada. A performance consiste numa perseguição aérea, com o auxílio do Dr. Nefário e dos minions. Quando o grupo finalmente consegue deter Vector, o protagonista precisa convencer as meninas do seu arrependimento, selado na promessa de nunca mais abandoná-las. Nesse momento, o protagonista assume seu papel de pai, mostrando-se um vilão regenerado.

Figura 5 - Esquema do percurso narrativo de Gru.

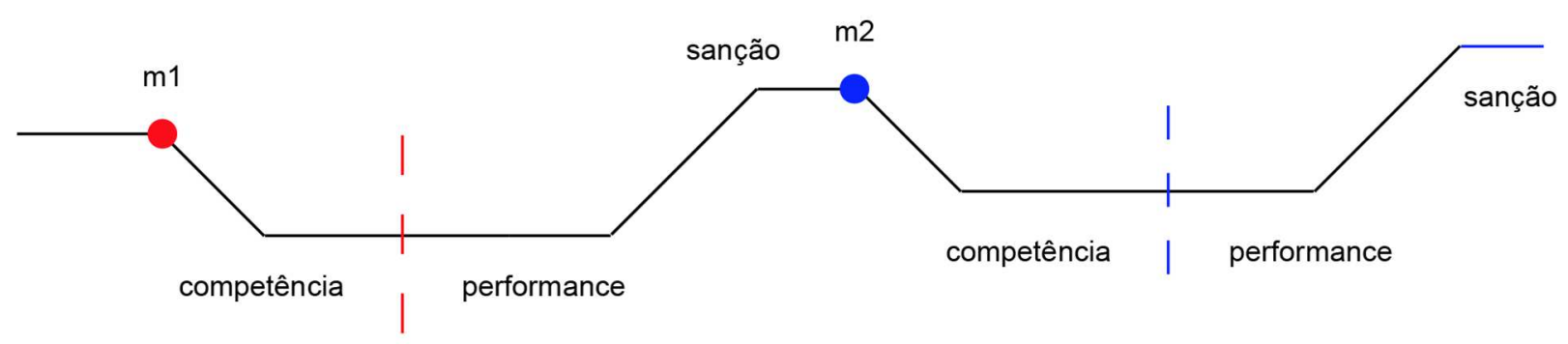

Fonte: elaborado pelos autores (2017).

É importante observar que os valores inscritos nos objetos (tanto de valor quanto modal) se alteram entre os dois arcos narrativos. No primeiro, o objeto de valor perseguido por Gru é o reconhecimento como maior vilão. E o objeto modal (instrumento que o sujeito utiliza para atingir seu objetivo final) é a adoção das meninas órfãs. No segundo arco, o objeto de valor é a redenção, na qual Gru percebe que para ele o mais importante era o amor da família construída com as meninas órfãs. Para atingir esse objetivo, o objeto modal foi a sua própria coragem, atestada pelo conjunto de suas proezas heróicas na performance da perseguição ao rival.

\subsection{Nível discursivo}

No objeto analisado, a actorialização explora Gru, o personagem principal, como alguém que passou a vida querendo se provar: nunca teve seu valor reconhecido pela mãe, que ignorava reiteradamente suas habilidades criativas, e na comunidade vilã por ser considerado um vilão ultrapassado. Ao longo dos filmes da série, esse padrão se repete, com seu esforço em se provar um bom pai e com a necessidade de provar que suas habilidades de ex-vilão podem ser úteis para a Liga Anti-vilões. 
Entre os demais personagens relevantes para a narrativa, ganham destaque as meninas órfãs (Margô, Edith e Agnes), devido a seu papel de inversão de sentido nos objetivos do protagonista; o Dr. Nefário (ajudante de Gru), Vector (o antagonista da narrativa), a mãe de Gru, responsáveis pelas tomadas de decisões com o objetivo de provação; e os minions, ajudantes de Gru em suas missões, que não veem distinção entre participar de um crime e ficar em casa brincando com as meninas, uma vez que seu propósito está ligado a seguir e auxiliar seu mestre.

A ambientação do filme é caracterizada por elementos arquitetônicos e culturais que remetem aos Estados Unidos - como as escoteiras vendendo biscoitos de porta em porta, os parques de diversão e o clássico copo de café. Outros espaços relevantes para o desenvolvimento do sentido da narrativa são a casa de Gru e a fortaleza de Vector, que refletem dois ambientes domésticos distintos. Enquanto a casa de Gru é antiga, repleta de objetos de tortura como sarcófagos, armaduras e armas que remetem à idade média, a fortaleza de seu antagonista é moderna, marcada pela cor branca e por inúmeros recursos tecnológicos. Reforçando tal contraste plástico, pode-se também perceber uma estética steampunk nas ferramentas, armas, utensílios e veículos utilizados por Gru. Pelo conjunto dos objetos cênicos, assim como pelos recursos tecnológicos à disposição dos personagens do filme, pode-se depreender que a história se passa num tempo contemporâneo, constituindo-se de dois momentos narrativos distintos: um tempo presente, no qual a ação principal se desenrola, e alguns flashbacks que recuperam memórias da infância do protagonista.

Na dimensão semântica do nível discursivo, encontram-se a tematização e a figurativização do texto analisado. Para a semiótica, uma figura é um elemento que um dado texto toma emprestado do mundo real, ou seja, utilizado no espaço discursivo em referência a algo concreto que se pode reconhecer da própria experiência. No filme em questão, podemos tomar como exemplos de figuras o cachecol que Gru usa ao redor do pescoço, sua casa, seu carro, seu cachorro, ou qualquer outro elemento concreto. A figuratividade é, nestes termos, aquilo que um texto tem de mais acessível ao seu destinatário, posto que se apresenta como um conjunto coerente de aspectos reconhecíveis ao seu leitor. Da mesma forma, a tematização é um procedimento que o autor do texto empreende no sentido de construir uma primeira camada de significação já abstrata, a partir das figuras utilizadas. Em outras palavras, um tema é um investimento abstrato relativo às figuras utilizadas. 
Um dos temas abordados no filme é a notoriedade, representada pela disputa entre os personagens pela figura da lua. Decididos a conquistar o posto de maior vilão da história, ambos os personagens seguem esse objetivo. Outro tema explorado é a rejeição enfrentada por Gru diante da atitude de desinteresse da mãe, a qual também aparece pela rejeição que Vector experimenta com o pai e que por fim está na base do abandono parental das crianças no orfanato. $O$ autoritarismo é outro tema identificado, em especial no relacionamento entre a responsável pelo orfanato e as órfãs. O tema rivalidade aparece durante toda narrativa, representado pela competição entre Gru e Vector. Ao final da narrativa, os temas redenção e regeneração emergem a partir da reiteração do conceito de família, delineado na nova relação entre o protagonista e as meninas órfãs.

\section{ARTICULAÇÕES ENTRE O CONTEÚDO E A FORMA NO DESIGN DE PRODUÇÃO}

A partir da discussão das estruturas figurativo-narrativas do filme, o que pode ser relacionado ao chamado Plano do Conteúdo, é importante observar que uma obra cinematográfica se realiza pela transposição de conteúdos verbais (o roteiro, a sinopse, o storyline, entre outros) para o registro audiovisual. Em outras palavras, um filme é a tradução intersemiótica para imagem e som (articulados) de um conteúdo inicialmente verbal. Nesse sentido, a construção audiovisual pressupõe uma série de definições plásticas necessárias à perfeita harmonização entre o universo narrativo explorado e as formas visuais e sonoras a serem produzidas.

Uma análise plástica de Meu malvado favorito permite identificar como foram alinhados os elementos apontados no percurso narrativo da história ao conjunto de formantes plásticos empregados na composição visual da obra. Tais elementos constituem o chamado Plano da Expressão, pressuposto em todo sistema de linguagem, relacionado ao conjunto dos ordenamentos plásticos produzidos para a construção do sentido de um texto, seja ele um filme, uma poesia, um objeto de design, uma história em quadrinhos, uma escultura, entre outros.

Metodologicamente, a análise do plano da expressão de um texto envolve a identificação dos chamados contrastes plásticos. Estes são pares de termos opostos relativos aos formantes do plano de expressão, organizados por oposição. Claro e escuro, reto e curvilíneo, preto e branco, geométrico e orgânico são alguns exemplos desses contrastes, organizados no Plano da Expressão em diferentes categorias de formantes. Temos formantes cromáticos, ligados à cor, eidéticos, 
ligados às formas, formantes topológicos, ligados às posições dos elementos, e ainda os formantes matéricos, ligados às propriedades materiais dos textos.

A narrativa aqui analisada traz, por meio da disputa entre os dois vilões, a mudança do simulacro de "vilão" que está acontecendo. Gru representa o vilão à moda antiga - macabro, laboratórios secretos, recursos escassos, instrumentos de tortura - e Vector representa o vilão atual, o nerd, dotado de maior tecnologia e com muitos recursos financeiros.

Analisando o plano de expressão do filme, os contrastes plásticos observados no visual das personagens antagônicas (Gru x Vector) são (figuras 06 e 07): cromático (preto x branco; insaturado x saturado; escuro x claro); eidético (reto x curvo; decadente x ascendente); matérico (sujo x limpo; velho x novo; texturizado $\mathrm{x}$ liso) e topológico (alto x baixo; esguio x curvilíneo).
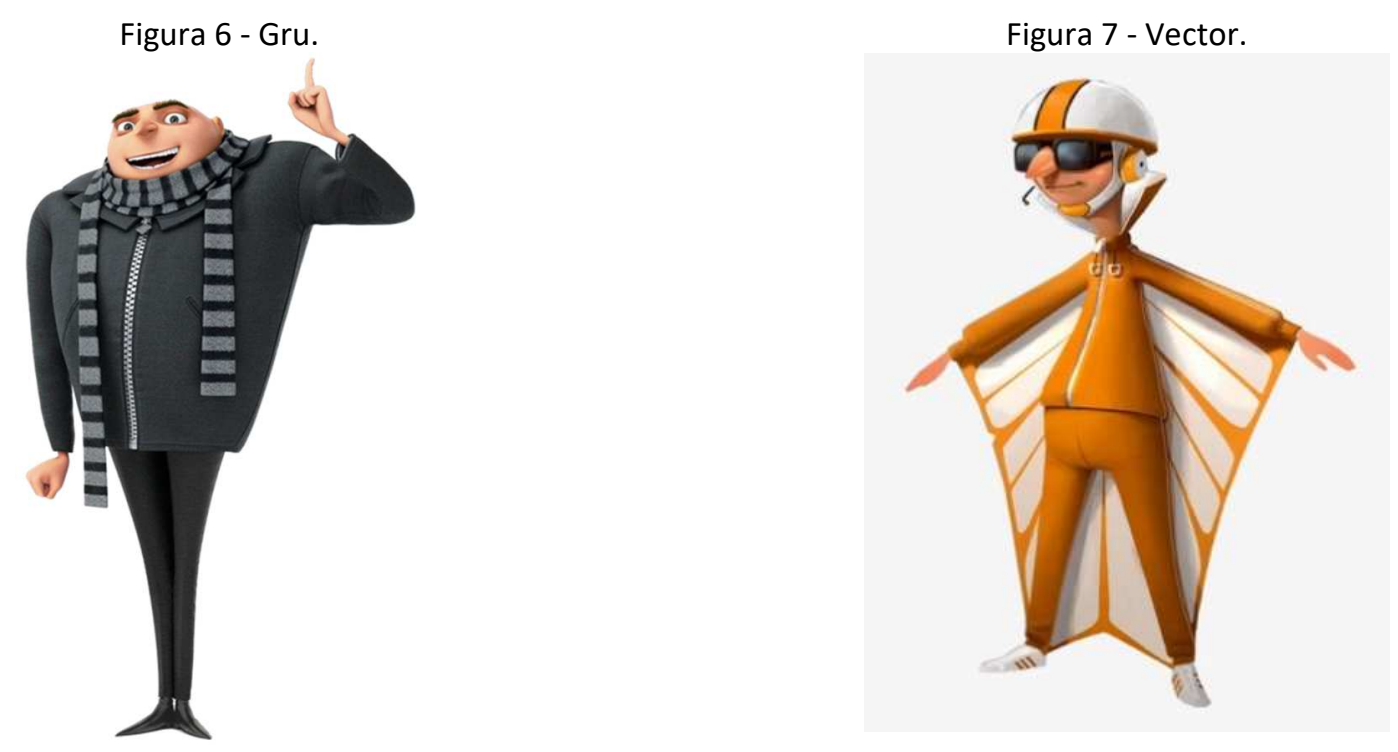

Fonte: frames extraídos do filme Meu malvado favorito.

No plano do conteúdo encontra-se a materialização do significado. Observando os contrastes do plano de conteúdo, no caso dessa análise a comparação entre Gru e Vector como simulacros de "vilão", cria-se a relação com os pares encontrados no plano de expressão. Assim, têm-se as chamadas operações semissimbólicas, obtidas a partir das relações do plano de expressão e plano de conteúdo. Para ilustrar essa relação entre o simulacro de vilão abordado na narrativa, um bom exemplo para comparação se dá entre as casas dos dois personagens (figuras 08 e 09), que trazem os pares opostos apresentados anteriormente em sua arquitetura. 
Figura 8 - Casa do Gru.

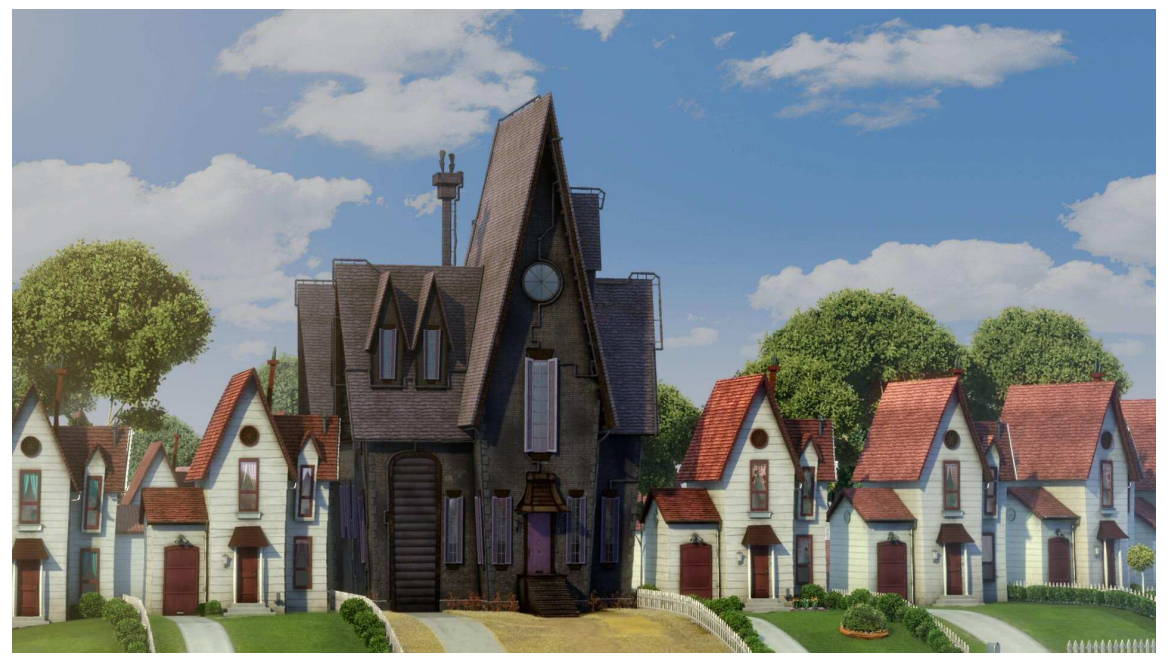

Fonte: frame extraído do filme Meu malvado favorito.

Figura 9 - Casa do Vector.

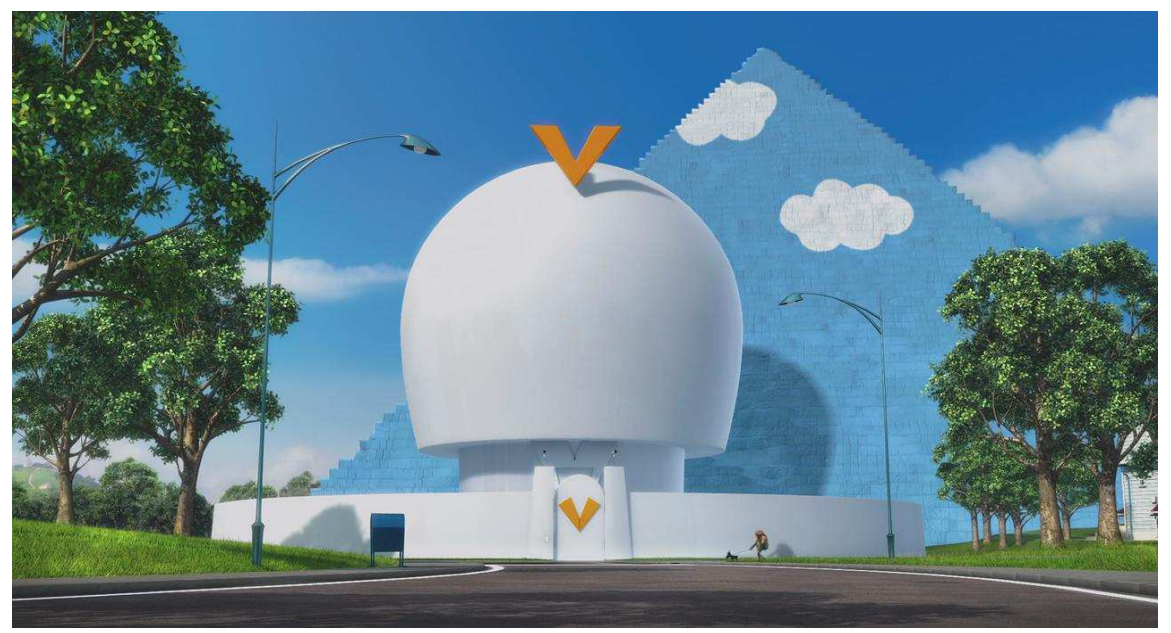

Fonte: frame extraído do filme Meu malvado favorito.

Ainda com relação aos aspectos plásticos que perfazem a forma dos objetos cênicos do filme, pode-se observar que o design dos veículos dos dois personagens em situação de antagonismo busca evidenciar a diferença entre ambos, na medida em que expõe qualidades semânticas diametralmente opostas (figura 10 e 11). 
Figura 10 - Veículo do Gru.

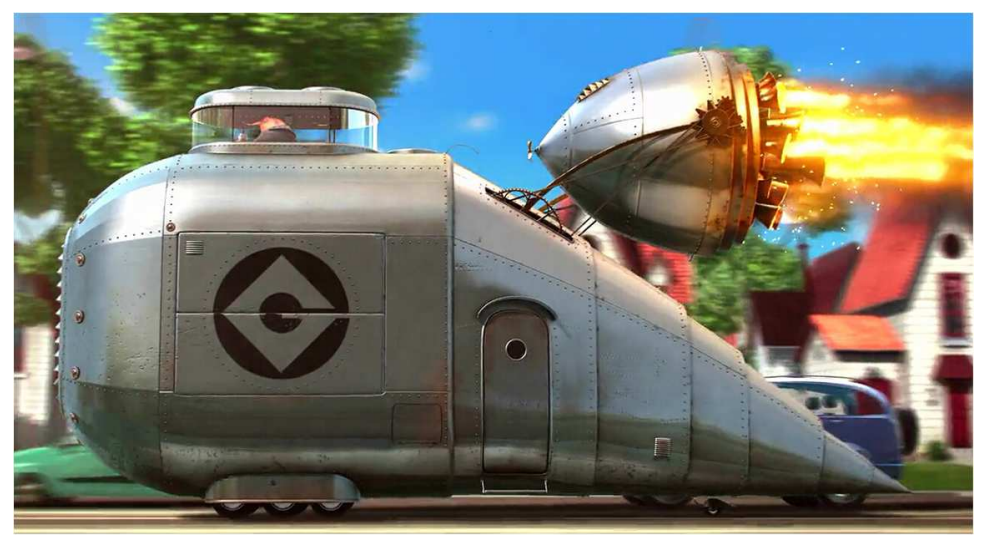

Fonte: frame extraído do filme Meu malvado favorito.

Figura 11 - Veículo do Vector.

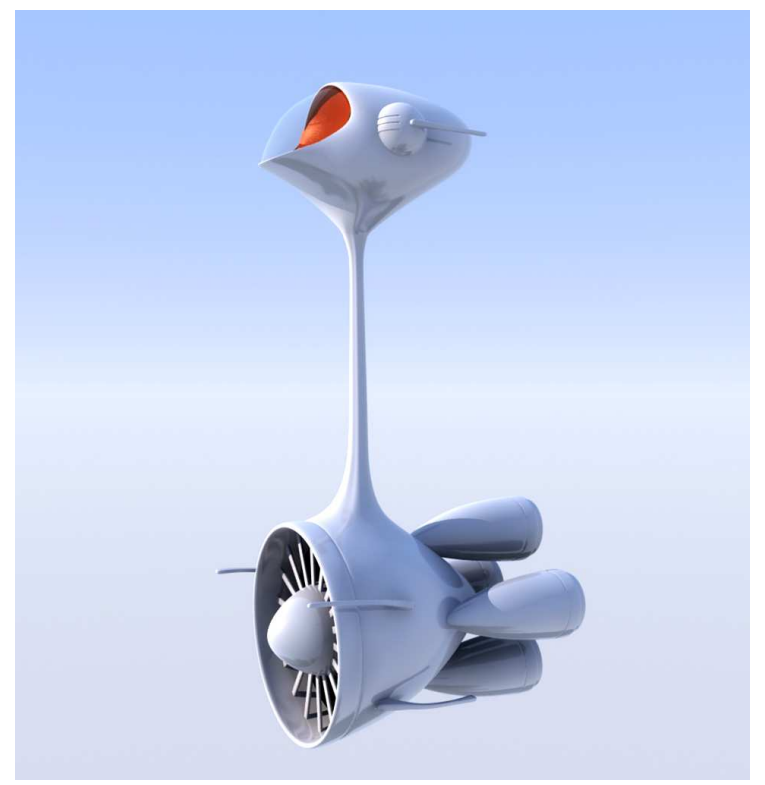

Fonte: frame extraído do filme Meu malvado favorito.

\section{CONSIDERAÇÕES FINAIS}

A partir da análise apresentada, foi possível observar que a configuração plástica e visual dos elementos em "Meu malvado favorito" estruturou a construção das identidades opostas dos dois personagens, o que demonstra a lógica narrativa da atividade do design. Por meio da criação de objetos, tais quais casas, armas, vestimentas e veículos, o design de produção formatou elementos fundamentais à estrutura diegética do filme, manifestada também na paleta cromática, nas formas gráficas e nas texturas, construindo a relação de antagonismo na narrativa audiovisual. 
Dessa forma, a plasticidade da animação teve importante papel na materialização do significado de antagonismo que a produção desejava apresentar, ao utilizar elementos visuais para dar forma aos conceitos abstratos dos diferentes simulacros abordados na conceptualização dos personagens.

\section{REFERÊNCIAS}

BARROS, Diana Luz Pessoa. Teoria semiótica do texto. 5. ed. São Paulo: Ática, 2011.

FIORIN, José Luiz. Elementos de análise do discurso. São Paulo: Contexto, 2015.

GREIMAS, Algirdas Julien. Sobre o sentido: ensaios semióticos. Rio de Janeiro: Vozes, 1975.

HOLLIS, Richard. Design gráfico: uma história concisa. São Paulo: Martins Fontes, 2001.

MEU malvado favorito. Direção: Pierre Coffin; Chris Renaud. Produtor executivo: Sergio Pablos. Estados Unidos: Universal Pictures, 2010. DVD (95 min). 